\title{
Educar para de-construir procesos racistas de discriminación social
}

\section{Deconstructing Racist Processes of Social Discrimination Through Education}

DOI: https://doi.org/10.32870/dse.v0i13.232

\author{
Rodrigo Zárate Moedano*
}

Resumen: Este artículo describe un proceso de investigación y educación participativo de enfoque etnográfico realizado con estudiantes de licenciatura de diversos programas de la Universidad Veracruzana, jóvenes de orígenes étnico-geográficos, orientaciones sexuales y niveles socioeconómicos diversos. Desde los conceptos de imaginario social, identidad y discriminación social, se analiza cómo es y cómo opera el entramado simbólico que justifica las desigualdades en el marco de la nación. Por medio de una intervención pedagógica que entreteje educación popular con miradas críticas de la educación intercultural y la educación para los medios, los estudiantes analizaron en grupos focales representaciones diversas de sujetos "indígenas", "españoles/güeros", "negros" y "mestizos", visibilizando y contrastando diferencias e inequidades. Además, la información generada se complementó con entrevistas a profundidad, observación participante y la elaboración de historias de vida, y se analizó de qué manera los imaginarios de los estudiantes estructuran sus procesos de construcción identitaria. Palabras clave: imaginarios, identidad, racismo, educación intercultural, educación para los medios.

\begin{abstract}
Abstract: This article describes a participatory process of research and education with an ethnographic approach. The research was conducted with undergraduate students of various educational areas, from diverse ethnic and geographical origins, sexual orientations and socioeconomic levels, in the main campus of Universidad Veracruzana, a Mexican public university. Based on the concepts of social imaginary, identity and social discrimination, this article analyzes the symbolic framework that justifies inequalities within the nation, and how it operates. Through an educational program that interweaves popular education, with critical approaches to intercultural education and media education, students analyze representations of "indigenous", "white people", "black" and "Mexican" subjects, contrasting their differences and making inequities visible. Data collection was conducted through focus groups, in-depth interviews, participant observation and life stories, to analyze how the students' imaginary structures their identity construction processes. Key words: social imaginary, identity, racism, intercultural education, media education.
\end{abstract}

\section{Introducción}

En México, la Constitución garantiza la igualdad de todos los ciudadanos; sin embargo, las prácticas sociales contradicen sistemáticamente ese principio legal, por ello hay grupos sociales con características determinadas que experimentan condiciones de privilegio o de desventaja. En ese marco de desigualdad, los pueblos originarios ocupan de forma recurrente las posiciones más bajas

* Comunicólogo con maestría en Tecnología Educativa y estudios avanzados en Historia del Cine, doctorante en Investigación Educativa. Docente y realizador audiovisual en la Universidad Veracruzana. Líneas de investigación: la reproducción del racismo y la convergencia entre educación para los medios y educación intercultural. Correo electrónico: rodrigo. zarate.moedano@gmail.com 
de la estructura socioeconómica del país. Por esa razón, se considera que la descolonización de México "fue incompleta" (Bonfil, 2010: 11), pues si bien se obtuvo la independencia frente a España, "no se eliminó la estructura colonial interna" y los grupos en el poder han seguido reproduciendo el punto de vista del colonizador desde su posición de privilegio.

En ese orden de colonialismo interno (González Casanova, 2003: 3), como pueblos dominados se les impone el nombre de "indios", 1 que busca borrar la vasta diversidad que los caracteriza (Gutiérrez Chong, 2001: 66), así como un sistema político, económico, social y cultural ajeno y radicalmente opuesto a los sistemas generados por sus grupos de procedencia. Asimismo, habitan en un territorio sin gobierno propio y las decisiones políticas que toman desde su diferencia cultural deben ceñirse a las regulaciones impuestas por el gobierno central. Además, estructuralmente la economía de mercado les ofrece condiciones de explotación severas con salarios bajos y poco reconocimiento social.

Dentro de ese sistema de dominación, las identidades "indias" o "indígenas" están cargadas de prejuicios negativos, por ello seis de cada diez sujetos adscritos a esas identidades reconocen la discriminación como su principal problema, además de que encuentran conveniente no explicitarlas cuando buscan empleo (CONAPRED, 2011). De esa forma, las condiciones de marginación que experimentan en su vida cotidiana se vinculan directamente a procesos estructurales y recurrentes de discriminación.

El propósito de este artículo es describir cómo es y cómo opera el entramado simbólico que justifica las desigualdades que padecen quienes son o parecen ser "indios" o "indígenas", mostrar la manera en la que ese entramado simbólico puede estructurar sus procesos de construcción identitaria y analizar de qué modo puede un proceso educativo y de investigación colaborativa detonar la de-construcción y re-significación de sus imaginarios y sus identidades. Para lo cual centraré mi análisis en los casos de dos chicas que se asumen como "no indígenas", al mismo tiempo que reconocen como "indígenas" a miembros de sus familias. Dos jóvenes que, por su formación académica y su militancia política, eran parte de la vanguardia crítica del grupo de estudio, ambas matriculadas en el último semestre de sociología y militantes activas de un colectivo feminista: Flor, originaria de Chetumal, ciudad capital del estado de Quintana Roo y Raquel, originaria de Chicontepec, una ciudad pequeña en el norte del estado de Veracruz. ${ }^{2}$

\section{El proceso de construcción de conocimientos}

La investigación de la cual se desprende este artículo tuvo un enfoque etnográfico (Rockwell, 2009) y se desarrolló en colaboración con los sujetos de estudio: un grupo de estudiantes univer-

1 En consecuencia, con el posicionamiento teórico, histórico y político del estudio, a lo largo del artículo las categorías étnicas y nacionales empleadas aparecerán entrecomilladas, para enfatizar su carácter arbitrario de constructo (por ejemplo "indio" y "negro" o "mexicano" y "español").

2 Acordé con las estudiantes cambiar sus nombres reales para preservar su anonimato. 
sitarios. El objeto de análisis fue la relación entre los imaginarios de los estudiantes acerca de las identidades que protagonizan el "mito fundacional" de la nación y sus procesos de construcción identitaria. El trabajo de campo tuvo lugar en el marco de un taller de producción audiovisual que diseñé e implementé con el propósito explícito de construir un escenario de investigación doctoral. ${ }^{3}$ El taller se llamó Documentar la diversidad y lo impartí a lo largo de un semestre, entre febrero y junio de 2015, en el campus Xalapa de la Universidad Veracruzana (UV).

Asumiendo que los imaginarios dominantes como instrumentos del poder se instituyen verticalmente de arriba hacia abajo, desde grupos sociales que ocupan posiciones de privilegio, elegí trabajar con estudiantes universitarios porque en México el acceso a la educación superior es privilegio exclusivo de una minoría, que estructuralmente no es "indígena", y si lo es probablemente no lo reconoce públicamente. Y decidí desarrollar la investigación en una universidad pública como la UV porque desde 2009 sus programas de trabajo institucionales establecieron la interculturalidad como uno de sus ejes rectores, y porque de una u otra forma han contemplado impulsar la adopción transversal del enfoque intercultural en todos sus programas y/o apoyar a estudiantes en condiciones desfavorables por diferentes formas de exclusión, en particular "estudiantes indígenas".

Además, elegí desarrollarla en el Campus Xalapa porque, siendo la UV uno de los centros públicos de educación superior más importantes del sureste mexicano, y Xalapa sede central del poder estatal y universitario, atrae no sólo a estudiantes de diversas partes del estado de Veracruz, sino de otros estados de la república mexicana y en menor medida extranjeros, pero, en todo caso, estudiantes con especificidades identitarias muy diversas.

Por otra parte, el taller tuvo como objetivo facilitar que los estudiantes contrastaran representaciones radicalmente opuestas de las identidades que componen el imaginario de nación. Asimismo, tuvo como propósito crear condiciones favorables para que los estudiantes reflexionaran, individual y colectivamente, acerca de cómo son representados los sujetos "indígenas", "españoles/ güeros", "negros" y "mestizos" en las narrativas difundidas por medios de comunicación como el cine, la televisión y el internet, así como en narrativas de los ámbitos familiar y escolar.

Por esa razón, los procesos de diseño e implementación se nutrieron teórica y metodológicamente de la pedagogía de Paulo Freire (2005), así como de perspectivas críticas de la educación intercultural (Walsh, 2010) y la educación para los medios (Kellner y Share, 2007); para reunir al grupo de estudio, en enero de 2015 convoqué a estudiantes de licenciatura a participar en el taller Documentar la diversidad. El anuncio se difundió masivamente por medio de los canales de comunicación electrónicos de la UV y respondieron a él 55 estudiantes, de los cuales al final únicamente 43 cumplieron con el requisito de tener una entrevista personal de selección conmigo.

3 Con el propósito de explicitar el posicionamiento desde el cual he conducido la investigación, renuncio a emplear la retórica científica clásica, impersonal y aséptica, y adopto la primera persona del singular, reconociendo mi participación en el proceso como parte de un "nosotros", un grupo de "mexicanos" moldeados por un imaginario de nación racista. 
En esa entrevista describí mi proyecto de investigación doctoral en términos generales y les informé que su participación en el taller implicaba participar en la investigación. Acordamos que accedían al taller de forma gratuita a cambio de colaborar como co-autores en la investigación, asumiendo que ellos eran "dueños" de la información recolectada a partir del registro de sus prácticas y, por lo tanto, participarían en validar la interpretación que yo hiciera en grupos focales de reflexividad.

Además, para orientar el proceso de selección, llenaron un cuestionario que tenía por objeto conocer sus datos generales (edad, género, licenciatura, semestre), su nivel socioeconómico, su origen étnico-geográfico y orientación sexual, así como la disponibilidad de horarios para asistir al taller. El criterio de selección fue tratar de reunir a un grupo de 20 estudiantes que representara la mayor diversidad posible de sujetos en relación con el programa académico que cursaban, su género, su orientación sexual, así como su origen geográfico y/o étnico. ${ }^{4}$

Ya como parte de las actividades del taller, formé cuatro grupos focales monotemáticos en los cuales los estudiantes analizaron cómo diferentes narrativas representan de formas distintas a sujetos "indígenas", "españoles/güeros", "negros" y "mestizos". Asumiendo que todo conocimiento es cuestionable, el objetivo de los grupos focales fue llevar a cabo la de-construcción de las representaciones analizadas; es decir, desarrollar lecturas subversivas y no dogmáticas que fragmentaran los textos buscando "fenómenos marginales, anteriormente reprimidos por un discurso hegemónico", y que además como resultado generaran textos alternativos (Krieger, 2004: 184).

El propósito era que los estudiantes miraran y escucharan críticamente para identificar cómo se articulan y pueden articularse los componentes de una determinada representación para producir diferentes tipos de significados, para facilitar que rompieran con la lógica interpretativa dominante, "sedimentada" y naturalizada (Molina Valencia, 2013: 50), y tematizaran lo que comúnmente se descarta, lo que habitualmente permanece oculto, los márgenes, los significados periféricos, lo que escapa de las representaciones dominantes.

Por otra parte, para contrastar y complementar los testimonios que emergieron de los grupos focales y mis observaciones en campo, realicé también dos series de entrevistas a profundidad; con base en toda la información recopilada, redacté una historia de vida de cada uno de los seis estudiantes que elegí como casos de especial interés. Asumí que reconstruir sus biografías me permitiría identificar sus "percepciones, intereses, dudas, orientaciones, hitos y circunstancias que -desde su perspectiva- han influido significativamente en ser quienes son y en actuar como lo

4 De los 43 estudiantes entrevistados (matriculados en 23 programas de licenciatura diferentes), admití 20 (matriculados en 13 programas diferentes de las seis áreas académicas en las que administrativamente se divide la Universidad Veracruzana: Artes, Ciencias biológico agropecuarias, Ciencias de la salud, Económico administrativas, Humanidades y Técnica). De ellos, doce eran mujeres y ocho hombres, doce se habían declarado heterosexuales y ocho homosexuales o bisexuales; cuatro habían declarado que sus abuelos hablan alguna lengua originaria, uno se había declarado afrodescendiente; seis eran originarios de Xalapa, capital del estado de Veracruz, siete del interior del estado y seis de otras entidades federativas (Oaxaca [2], Quintana Roo [1], Coahuila [1], Distrito Federal [2]). Y de acuerdo con lo declarado, inferí sus condiciones socioeconómicas y admití equitativamente estudiantes de nivel bajo, medio y alto. 
hacen" (Bolívar y Domingo, 2006: 6); el propósito fue analizar de qué manera se relacionan sus experiencias individuales con los contextos histórico-sociales concretos en los que han desarrollado y desarrollan sus trayectorias vitales; en particular analizar de qué manera han contribuido sus experiencias de vida en los ámbitos familiar y escolar, a moldear sus imaginarios de la identidad y la alteridad en el marco de la nación.

Clasifiqué y organicé la información contenida en las transcripciones de los grupos focales y las entrevistas a profundidad, identifiqué recurrencias, divergencias y relaciones desde la perspectiva del análisis crítico del discurso (Van Dijk, 2003). Además, desde el enfoque etnográfico y a lo largo del proceso de construcción de conocimientos, busqué identificar las relaciones que articulan las prácticas de los sujetos con los marcos institucionales que las regulan; es decir, observar, interpretar y describir las prácticas de los sujetos de forma situada para visibilizar lo "no evidente" y "documentar lo no-documentado" (Rockwell, 2009: 21). En este caso, un fenómeno social que la academia reconoce pero que la vida política institucional y la vida cotidiana niegan: el racismo en nuestro imaginario de nación e identidad nacional.

De modo complementario y paralelo, para contextualizar las experiencias de los estudiantes en el marco de la historia nacional, hice una reconstrucción de cómo se ha reproducido la dominación colonial de la otredad en la nación. Además, finalmente, con el propósito de desarrollar un proceso de doble reflexividad (Dietz, 2012), expuse a los estudiantes los hallazgos del estudio y los comentaron en dos sesiones de grupo focal, y este artículo se fundamenta en la perspectiva que emergió del diálogo entre estudiantes-investigadores y facilitador-investigador.

\section{Antecedentes históricos del estudio La dominación colonial de la otredad}

Antes de analizar los casos de Flor y Raquel, considero de gran relevancia y pertinencia describir el contexto histórico de largo aliento en el cual se enmarcan, y empiezo por señalar que, desde los primeros encuentros entre pobladores originarios de América y conquistadores europeos, se enfrentaron dos imaginarios radicalmente opuestos. Que como en todas las interacciones sociales en contextos de diversidad, cada grupo echó mano de los conocimientos que había construido históricamente acerca del mundo, para identificar cuáles eran las características distintivas de "ellos" y de "nosotros", así como para interpretar las diferencias entre ambas identidades.

Desde la perspectiva de los conquistadores, en la vida cotidiana de los nativos americanos tenían lugar prácticas bárbaras, salvajes y primitivas que, en Europa, producto del avanzado nivel de progreso de su civilización, se habían superado muchos siglos atrás. En consecuencia, asumieron pertenecer a una comunidad superior, más civilizada que la de los "indios", y desde esa posición empezaron a disputarles el control político, económico y religioso del vasto y rico territorio que terminaría por llamarse Virreinato de Nueva España. 
Consumada la conquista, los vencedores impusieron su modelo civilizatorio como eje único de desarrollo, así como la gramática de identidad/alteridad que garantizaba la reproducción del modelo; es decir, los patrones culturales desde los cuales estructuraban su percepción de lo propio y lo ajeno, así como su interacción con sujetos y grupos de identidades diversas (Gingrich, 2004). Al fungir como sustrato simbólico, esa gramática le dio forma al sistema social de castas que instituyó una jerarquía de dominación estructurada en torno a la oposición entre civilización y barbarie.

Desde ese imaginario, la pureza de la sangre española garantizaba la reproducción de la civilización, al mismo tiempo que la "contaminación" producida al mezclarla con sangre de "indios" y "negros" la comprometía. Por ello, con base en el peso relativo de los componentes "indio", "negro" y "peninsular", el sistema social de castas le asignaba un rango diferente a cada configuración identitaria (Bonfil, 2010: 40). Así, a lo largo de casi tres siglos, dentro del sistema social de castas, la identidad "peninsular" se ubicó en la cima de la jerarquía y le aseguraba a quienes fueran identificados con ella, un acceso privilegiado a recursos económicos, poder político y reconocimiento social. Al mismo tiempo, limitaba el acceso a esos bienes a los sujetos y grupos que eran identificados como inferiores, los "criollos", "indios", "negros" y demás castas "mestizas", lo cual garantizaba la continuidad del sistema de dominación colonial.

En ese contexto, de acuerdo con el imaginario de la época, los "criollos", aunque eran hijos de "peninsulares", eran "españoles" de segunda pues cargaban con el estigma de haber nacido en suelo americano (Anderson, 2005: 95). A los "indios" se les creía incapaces de valerse por sí mismos, sin la tutoría de sujetos "superiores", pues eran concebidos como salvajes menores de edad con todo por aprender. Los "negros", con aún menos reconocimiento social que los "indios", ni siquiera eran concebidos como humanos, sino como animales. Y los miembros de castas "mestizas", al tener sangre "india" y/o "negra", eran considerados en mayor o menor medida como seres degradados e indeseables.

En relación con los "mestizos", es relevante señalar que, desde la gramática identidad/alteridad que estructuraba el sistema social de castas, se prodigaba un especial aprecio a "la blancura" de los sujetos como marca de superioridad, en contraposición con el desprecio y menosprecio hacia "lo moreno" y "lo negro". Por ello, descender de "peninsular" e "india" era preferible a descender de "peninsular" y "negra" (Gómez y Sánchez, 2012: 34 y 35). Y de esa forma, el sistema social de castas instituyó y legitimó lo que Giménez (2007: 38 y 39) nombra discriminación social; es decir, el intercambio recíproco pero desigual de reconocimientos evaluativos entre sujetos y grupos que ocupan posiciones asimétricas en el espacio social. Intercambio que, en la diversidad, deriva en un trato inequitativo para sujetos y grupos de identidades distintas, así como en acciones negativamente orientadas de los grupos dominantes hacia los grupos dominados.

Finalmente, como grupo privilegiado, los "criollos" accedieron a los recursos simbólicos y materiales necesarios para tratar de llevar a la realidad el orden social que habían imaginado (Anderson, 2005: 93). De tal suerte que, en 1810, luego de casi tres siglos de dominación colonial 
española, los pobladores dominados del Virreinato de Nueva España, encabezados por un grupo de "criollos", tomaron las armas buscando arrebatarle el control político y económico del territorio a los "peninsulares", para instituir un Estado nacional independiente.

\section{La dominación colonial de la otredad en la nación}

Los "criollos" que lideraron la lucha de Independencia en el siglo XIX se habían educado conociendo y admirando los desarrollos científicos generados en Europa durante la Ilustración en el siglo XVIII, y tenían como referente de su lucha política dos hitos ocurridos a finales de ese mismo siglo, que suponían la concreción de los ideales heredados del siglo de las luces: la declaración de independencia de los Estados Unidos de América (1776) y el inicio de la revolución francesa (1789).

En consecuencia, el orden social que instauraron legalmente una vez consumada la independencia en 1821, se articuló con base en la tradición europea de pensamiento. Sin embargo, aunque la nueva república abolió la esclavitud, estableció la igualdad de todos los miembros de la nación y dejaron de usarse oficialmente los nombres de las castas para identificar a los sujetos, la gramática de identidad/alteridad del sistema colonial de castas no sufrió cambios sustanciales en su aprecio por "la blancura".

La gramática del Estado nacional mexicano le dio continuidad a la valoración positiva de "la blancura" como marca de lo civilizado y moderno, en oposición a la valoración negativa de "lo moreno" y de "lo negro" como marcas de lo incivilizado y primitivo. Y es probable que esa continuidad se haya dado porque los imaginarios desde los que actúan los sujetos no se transforman instantáneamente como consecuencia de un decreto legal, sino paulatinamente con base en procesos prolongados de interacción social. Porque aun cuando los imaginarios experimenten cambios radicales a través del tiempo, también sostienen continuidades, pues "todo simbolismo se edifica sobre las ruinas de edificios simbólicos precedentes, y utiliza sus materiales" (Castoriadis, 2013: 194).

Sin embargo, también es pertinente señalar como posible causa de la continuidad, que el pensamiento político conservador de la época tenía en su catálogo de obras admirables el Systema Naturae (1753) de Carl Von Linné. En esta obra clasificaba las "razas" humanas y luego de combinar observaciones, mediciones y comparaciones empíricas de cada grupo "racial" con juicios de valor moral, concluía que la "raza blanca" era superior a las demás, ya que presentaba una mayor cantidad de virtudes "congénitas" (Gómez y Sánchez, 2012: 41 y 42).

Posteriormente, ya durante la segunda mitad del siglo XIX, la dominación de la otredad en la joven nación "mexicana" se justificó utilizando como instrumento ideológico el llamado "racismo biológico". Este sistema de pensamiento establecía una línea divisoria entre humanos biológicamente superiores e inferiores y fundamentaba su lectura de la realidad articulando la clasificación

de las "razas" humanas de Linné, con una interpretación social de la teoría de la evolución postulada por el naturalista Charles Darwin en El origen de las especies (1859). 
Desde el darwinismo social se asumía que en un contexto de competencia capitalista tenían lugar procesos de selección natural como mecanismos de evolución social, ante los cuales únicamente sobrevivían los sujetos más aptos. Y a su vez, fundamentada en el darwinismo social, la eugenesia promovía la selección artificial de los más aptos. Es decir, llevar a cabo la "depuración" de las poblaciones controlando la reproducción de los sujetos, permitiendo procrear a los sujetos con rasgos identitarios "deseables" e impidiendo procrear a los sujetos con rasgos "indeseables".

De esa manera, mientras por medio del nacionalismo se buscaba generar una sensación de pertenencia a una comunidad fraternal y solidaria que difuminara las diferencias de la población, por medio del racismo se buscaba destacar las diferencias y abusar psíquicamente del Otro hasta dominarlo simbólica y materialmente. En consecuencia, se promovía un racismo de Estado, un racismo que las elites imponían para defenderse de las "amenazas biológicas" que se reproducían al interior del tejido social (Gómez Izquierdo, 2005: 125).

Por ello, para crear la sensación de pertenencia entre los grupos sociales que anteriormente estuvieron divididos en castas, las elites mexicanas establecieron el mestizaje entre padre "peninsular" y madre "india" como mito fundacional de la nación, como el origen común de todos los mexicanos. Y con el objetivo de continuar la relación de dominación sobre los pueblos originarios, construyeron al "indio" como inferior e indeseable para el progreso nacional; por ello, para ser parte de la nación los pueblos originarios debían "desindianizarse" (Bonfil, 2010), es decir, transformarse en "mestizos".

Así, aquel imaginario de nación, al concebir la homogeneidad como meta re-significó la identidad "mestiza", y de ser una identidad degradante en el sistema de castas, se transformó en el modelo de la identidad nacional. Por otra parte, los "negros" fueron construidos como un accidente de la historia, es decir, como los esclavos que alguna vez existieron y "desaparecieron sin dejar huella" al consumarse la independencia.

Mientras, los "indios" fueron construidos como seres con una inteligencia inferior, ajenos a "la razón" y anclados en una mentalidad primitiva generadora de supersticiones, atavismos fanáticos y atraso espiritual, el cual, a su vez, sustentaba una religión bárbara. Así, fueron construidos como un obstáculo para consolidar al país como una nación moderna, por lo cual, con el objetivo de "mejorar la raza" y "paliar el atraso cultural y tecnológico", el Estado nacional promovió la inmigración extranjera desde Europa (Castellanos Guerrero, 2005: 106).

Por ello, una vez instituida la nueva gramática dominante de identidad/alteridad en la vida nacional, los sujetos identificados como "indios" o "negros" siguieron accediendo a menores cuotas de recursos económicos, poder político y reconocimiento social, que los sujetos identificados como "mestizos". Además de que siendo "mestizo" el sujeto, mientras más blanco fuera y menos "indio" pareciera, mayor probabilidad tendría de acceder a una posición de privilegio en la sociedad nacional. 


\section{Consolidación y resquebrajamiento de la nación mestiza}

Ya a principios del siglo XX, como consecuencia del orden y el progreso promovidos por el régimen de Porfirio Díaz, parecía que el "indio" comenzaba a desaparecer irremisiblemente del mapa nacional. Entonces, aglutinados en parte como "zapatistas" en el contexto de la Revolución, los pueblos originarios asumieron la defensa de su identidad reclamando "tierra y libertad", pues controlar el territorio les permitía desarrollarse reproduciendo sus propias tradiciones culturales. Sin embargo, no fue el proyecto zapatista de nación el que triunfó, y el desarrollo del país siguió alineado con el proyecto civilizatorio de occidente, y en gran medida también con las gramáticas de identidad/alteridad precedentes.

Prueba de ello es la continuidad del racismo "anti-indio" en las políticas de identidad promovidas desde las elites antes y después de la Revolución (Gómez Izquierdo, 2005: 122 y 123). En particular destaca que su construcción del "indio" confirma los estereotipos y prejuicios racistas, que lo pintan "no sólo como pobre, pasivo, atrasado, sino también como criminal, fanático, amenaza potencial, vicioso"; y que justifican su subordinación estigmatizando su diferencia cultural como un lastre.

Concluido el periodo fundacional de inestabilidad y turbulencia, los gobiernos fueron consolidando su poder y su control sobre la población y el territorio, orientando sus acciones a profundizar el proceso de incorporación de los "indios" a la nación. En ese contexto, la fundación de la Secretaría de Educación Pública (SEP) en 1921, estableció un sistema educativo nacional centralizado, que institucionalizó el "indigenismo" para "redimir a los indios" y reforzar la identidad "mestiza". Redención que consistía en sustituir su identidad, en normalizar el "español" como idioma único y borrar de la faz de la nación los "dialectos primitivos" de los pueblos originarios.

La narrativa histórica sobre los orígenes de la nación retomó la perspectiva de las elites porfirianas, asumiendo el papel benefactor de la Conquista en relación con el México prehispánico salvaje y sanguinario. Punto de vista que, a su vez, había sido construido con base en la perspectiva de los vencedores, los testimonios escritos por soldados, cronistas y frailes católicos (Gómez Izquierdo, 2005: 143 y 144); por lo cual, también reproducía de algún modo la gramática de identidad/alteridad de los conquistadores.

Posteriormente, a partir de 1960, los libros de texto gratuitos elaborados desde el Estado han reproducido una particular construcción de la nación en escuelas públicas y privadas de todo el país; han definido las creencias, normas y valores comunes que orientan las prácticas de los sujetos, operando como referente en sus procesos de construcción de identidad y alteridad (Ramírez Lozada, 2003: 185 y 186), legitimando y naturalizando el poder de los grupos dominantes.

La historia patria oficial ha confirmado su vocación racista y colonialista modelando al "mestizo" como redentor de sujetos "primitivos", inferiores biológica, cultural y moralmente. Ha prescrito el mestizaje como vía de acceso a cierto reconocimiento social, por lo cual los "indígenas" que han rechazado o no han logrado mestizarse han seguido experimentando "la estigmatización, 
la explotación o el paternalismo racista, de blancos y mestizos" (Gómez y Sánchez, 2012: 23), y la identidad "indígena" se ha construido como indeseable e indigna.

La enseñanza de esa versión de la historia ha supuesto una "invasión cultural" (Freire, 2005), pues desde el poder ha dado forma al imaginario de los dominados inhibiendo su desarrollo autónomo, en lugar de transformar el imaginario que justifica su dominación. La acción pedagógica del Estado nacional se ha enfocado en convencer a los sujetos de su "inferioridad intrínseca" en relación con los sujetos de los grupos dominantes. Al respecto, es pertinente destacar que los sujetos tienden en primera instancia a valorar positivamente su identidad, lo cual tiene como consecuencia directa estimular su autoestima, el orgullo de pertenencia y la solidaridad grupal, así como la voluntad y la capacidad de resistir la penetración excesiva de elementos identitarios ajenos. Sin embargo, al enfrentarse sistemáticamente a representaciones negativas de su identidad, ya sea porque supone desventajas frente a otras identidades o porque hayan "introyectado los estereotipos y estigmas" que se les prescriben, los sujetos experimentan con facilidad "frustración, desmoralización, complejo de inferioridad, insatisfacción y crisis” (Giménez, 2009: 44).

Finalmente, dentro de un orden mundial caracterizado por la globalización de políticas neoliberales ya cuando el siglo XX concluía, el Estado mexicano instrumentó una serie de reformas que endurecieron las condiciones de dominación que experimentaban los pueblos originarios. Al mismo tiempo, el ciclo escolar 1992-1993 fue declarado "Año para el estudio de la historia de México", y se distribuyeron libros de historia que hacían una lectura del pasado acorde con los objetivos políticos del momento. Desdibujaban aún más la presencia "indígena" en la historia nacional, reducían el espacio dedicado a Zapata y los campesinos en la Revolución, así como el peso de sus reivindicaciones; además, sobrevaloraban la vida urbana en el México contemporáneo (Ramírez Lozada, 2003: 220 y 221).

Entonces, las acciones del Ejército Zapatista de Liberación Nacional (EZLN) vinieron a cuestionar la legitimidad del Estado mexicano y el imaginario racista de nación que promovía. El Estado fue puesto a prueba y aunque la existencia del EZLN resquebrajó la ilusión de la nación "mestiza", los grupos en el poder rechazaron establecer el diálogo horizontal entre "mestizos" e "indígenas" que proponían los Acuerdos de San Andrés (Gómez y Sánchez, 2012: 113). Ante la exigencia de cambio de "nuestros indígenas", la clase política "mestiza" dio continuidad al esfuerzo estructural y sistemático del Estado, para que el colonialismo interno siguiera siendo motor del desarrollo nacional, negando a los pueblos "indígenas" el derecho a existir diferentes en la nación.

\section{De-construir y re-significar identidades en el marco de la nación El caso de Flor}

Flor nació en diciembre de 1990 en Chetumal, Quintana Roo, donde habitan poco más de ciento cincuenta mil personas. Es hija única de madre soltera, pero creció en una familia extensa, habitando con su madre la misma casa que sus abuelos, una tía y un primo. Su madre, al igual que todos sus 
tíos y a diferencia de sus abuelos, hizo estudios superiores como licenciada en administración de empresas, y trabaja como empleada del gobierno federal en el servicio postal mexicano, mientras sus hermanas se graduaron y trabajan como maestras de nivel medio.

Las dos entrevistas que hice con ella fueron el 4 de marzo y el 8 de junio de 2015, en el aula donde desarrollamos las actividades del taller. En la primera le pedí me contara cómo había sido su vida familiar y cómo consideraba que había incidido en definir quién es; empezó por describir a su familia como "un matriarcado", cohesionada por un fuerte sentido "de comunidad, de pertenencia" y "muy católica". Me contó que ella forma parte de la primera generación de quintanarroenses, pues provienen originalmente de Yucatán y llegaron a Chetumal "por trabajo y porque había más oportunidades".

Con base en la información que me brindó durante el proceso de selección, al entrevistarla yo sabía que ni ella ni su madre hablaban maya, pero sus abuelos y dos hermanas de su madre sí. Por ello, cuando consideré oportuno le pregunté directamente: ¿sabes por qué tus abuelos no les hablaron en maya a tu mamá y a tus tíos? Y Flor respondió: "sí, porque querían que todos sus hijos fueran a la escuela, que tuvieran una carrera y todo eso; y sí se menospreciaba mucho el que uno hablara maya porque... eso era como para ignorantes".

Me contó que sus tías lo aprendieron "con esta onda de recuperarlo" y han tomado clases para ponerlo en práctica en sus lugares de trabajo: telesecundarias en "comunidades mayas". Me compartió que con ese mismo sentido de recuperar lo perdido, tiene ganas de aprender maya: "siento que está, que debo de aprenderlo... que es parte de mí; y lo hemos vivido como... más bien, como que no lo hemos querido mirar, o sea, como que nos enseñaron a darle la espalda porque hablar maya es símbolo de ser ignorante, ¿no?”

Cualidad de "ignorante" que vinculó con el origen rural y la falta de escolaridad del sujeto y, en ese sentido, al valorar qué categorías de estudio la describían con mayor precisión, señaló que "por los conceptos que se tienen", "se imagina como indígena a alguien que no ha salido de su comunidad, que no se sabe mover en una ciudad, con pocos estudios, retraído, este, o sea, es lo primero que se me viene a la mente cuando leo la palabra indígena ¿no?, alguien que tiene que ser protegido". Mientras en la segunda entrevista, cuando le pregunté: si llegas a un lugar y te encuentras con un grupo de personas, ¿cómo puedes saber que alguien es indígena? Señaló lo difícil que resultó responder a mi pregunta, porque "cómo responderla sin los estereotipos que nos han enseñado, que es como la manera más fácil de decir, ah, pues sí es indígena, pues mira cómo está vestido, mira cómo está hablando, o sea, está vendiendo algo".

También con base en narrativas familiares, construyó ciertos rasgos "típicos" de las identidades "indígenas" como objetos de reconocimiento social escaso y agresiones a su dignidad. Recordó, por ejemplo, que su madre se burlaba de ella por usar blusas "típicas" de Yucatán, que le decía "a donde sea que vayas... te van a tratar como te vean" y con sorna y reprobación la llamaba "Rigoberta Menchú". Y para explicarme el proceder de su madre, me reveló que ella "no usa esa 
ropa", que "es una señora que se arregla mucho, se pinta demasiado... intenta ser muy formal... una típica señora trabajadora de gobierno". Además, identificó la presión social en su familia como la causa definitiva para haber dejado de usar esas blusas que le "encantan".

Por otro lado, con base en prácticas que conoció y experimentó de primera mano en su trayectoria escolar, también construyó "lo indígena" como objeto de insultos y causal de discriminación social. En la segunda entrevista recordó que cuando cursaba la secundaria era habitual entre sus compañeros denostar usando expresiones como "eres una india" o "pinche indígena". Y en la primera recordó que, al cursar la preparatoria, se topó con gente que la trataba "diferente, en el sentido de que no te tratan educadamente porque piensan que por como te ves te pueden sobajar, ¿no?, entonces... me empecé a sentir así como 'no soy bonita' por ejemplo, fue así como mucha falta de confianza conmigo misma".

Recordó también que la infravaloración que hacía de sí misma la llevaba a asumirse estéticamente inferior a los sujetos extranjeros "güeros", a sentirse "como un bicho" junto a ellos tan "altos y despampanantes"; así como a definir con quién podía aspirar a tener una relación afectiva y con quién no, y en ese sentido recordó pensar cosas como: "ni siquiera me voy a fijar en él porque sé que no se va a fijar en mí..., porque se va a fijar en la más bonita", que no parece "indígena maya", como Flor se describe a sí misma.

\section{El caso de Raquel}

Raquel nació en septiembre de 1991 en Chicontepec, Veracruz, una ciudad de poco más de cincuenta mil habitantes. Es la segunda de tres hermanas y creció en "Chicón”, en una familia nuclear. Nuestra primera entrevista tuvo lugar el 1 de marzo de 2015, una mañana de domingo en un parque relativamente cerca de su casa en Xalapa y quedamos ahí a sugerencia suya.

En aquella ocasión le pedí me contara cómo había sido su vida familiar y cómo consideraba que había incidido en definir quién es; entonces me contó que sus padres son originarios de Piltepeco, un pequeño pueblo en el estado de Hidalgo, que hablan español y náhuatl, y ambos fueron los primeros miembros de sus respectivas familias en realizar estudios superiores. Provienen de familias campesinas, y desde la escuela primaria desarrollaron su trayectoria escolar en internados públicos para estudiantes "indígenas". Su acceso a la educación ha supuesto la posibilidad de mejorar sus condiciones de vida, dejar la incertidumbre y marginación del trabajo agrícola en la comunidad para disfrutar de la estabilidad y prosperidad del trabajo asalariado en la ciudad.

A diferencia de sus padres, Raquel y sus hermanas únicamente hablan español, lo cual me explicó como consecuencia de la formación que recibieron sus padres en el sistema educativo mexicano, pues les enseñaron a desdeñar sus rasgos de identidad "indígena”. Empezó por contarme la historia que ellos le han contado, que en los internados donde estudiaron la primaria eran reprendidos sistemáticamente por hablar en náhuatl: "se les queda como muy marcado que... los 
regañaban mucho en la primaria porque hablaban náhuatl y les ponían castigos ... muy severos por hablar náhuatl".

Luego me compartió que su padre siempre ha buscado "deslindarse" de su identidad "indígena”, y por ello decidió romper con la reproducción del náhuatl como primera lengua en su familia: "cuando se juntan y tienen hijos pues ya mi papá le dice a mi mamá que no nos enseñe náhuatl porque pues eso no nos va a servir". Lo cual sintetizó nueve meses después de nuestra primera entrevista en el grupo focal de reflexividad que realicé a finales de noviembre de 2015: "por todo esto de la imposición nacionalista de que lo indígena era menos, pues mi familia trató de borrar nuestro pasado indígena".

Además, cuando le pregunté cuál era su posición al respecto, respondió describiendo la cabecera municipal de Chicontepec y Xalapa, las dos ciudades donde ha vivido, como entornos en los cuales es inútil hablar náhuatl pues la lengua dominante es el español. Incluso recordó que algunas de sus compañeras de la secundaria que provenían de comunidades rurales "no hablaban náhuatl y no les interesaba"; esto la llevaba a pensar que "si ellas deberían hablarlo y no lo hablan, bueno entonces yo no veo por qué deba hablarlo".

Con base en el análisis de toda la información generada, entiendo que Raquel asume como consecuencia de la vida que han podido construir sus padres como profesionistas, el haber experimentado una vida con ciertos privilegios en comparación con algunos de sus compañeros de escuela; por ejemplo, vivir en la cabecera municipal y no en una comunidad rural marginada del acceso a servicios públicos, o tener una enciclopedia en su casa y viajar de vacaciones a Xalapa, a donde, al igual que a sus hermanas, tuvo también la posibilidad de mudarse para realizar sus estudios medios superiores y superiores.

Entiendo también que, asumiendo la identidad "indígena" como un lastre infamante, su padre ha dispuesto siempre del capital social y económico a su alcance para brindarles a Raquel y a sus hermanas experiencias de vida que profundizaran la ruptura con "lo indígena", con la vida en la comunidad. Por otra parte, en nuestra segunda entrevista, al hablarme de la tesis que estaba escribiendo, "Educación y empoderamiento de mujeres indígenas: Trayectorias en la Universidad Veracruzana", Raquel reveló que, aunque no lo apruebe, asume que socialmente la identidad "indígena" es un estigma que "naturalmente" busca esconderse.

Me señaló que al buscar sujetos de investigación su hipótesis era que "por el estigma que se ha hecho en torno a la comunidad", el contexto universitario dificultaría que reconocieran venir de una comunidad "indígena". Recordó pensar que podría ser incómodo preguntarles directamente "si ellas se asumían como mujeres indígenas"; sin embargo, lo hizo y sus reacciones la sorprendieron: "de las seis que entrevisté, al preguntarles si se auto describían como indígenas dijeron que sí, y a mí eso sí me sorprendió, porque pensé que no lo iban a decir".

Con base en el análisis de toda la información generada, entiendo que el "estigma" del que habla Raquel se fundamenta en gran medida en identificar los rasgos de identidad "indígena" como 
detonantes de prácticas discriminatorias; por ejemplo, al recordar las experiencias de sus padres como hablantes de náhuatl en el sistema escolar castellanizante, o bien, recordar a su padre actuando de forma prepotente y poco solidaria con los campesinos que buscaban su asesoría como ingeniero agrónomo, asumiendo estar en una posición de mayor reconocimiento y poder "por tener estudios".

De-construcción y re-significación de identidades desde el aula

De acuerdo con Raquel, los grupos focales fueron "espacios de libre pensamiento", sesiones de diálogo no exentas de conflictos, desde perspectivas forjadas en contextos histórico-sociales diversos, y desde posicionamientos disciplinares y políticos también diversos. En ellos se reflexionaba organizada y sistemáticamente de forma individual y colectiva, dialogando, conociendo múltiples perspectivas sobre la identidad y la otredad.

En el grupo focal acerca de cómo se construye "lo indígena", que desarrollamos el 12 de marzo de 2015, empecé por mostrarles una serie de imágenes extraídas de películas y programas televisivos, de comedia y melodrama, así como titulares periodísticos. También les pedí buscar en su memoria narrativas sobre "indígenas", sobre sus prácticas, experiencias de vida y culturas; esto hizo que emergieran imágenes y anécdotas diversas, escuchadas, observadas y/o experimentadas por los estudiantes.

Posteriormente, con base en el análisis y comparación de representaciones radicalmente distintas de "lo indígena", un comercial de promoción turística gubernamental y un cortometraje documental sobre un grupo de rock, ${ }^{5}$ Flor evidenció la diferencia entre los posicionamientos desde los cuales fueron construidos los relatos analizados: "mientras uno intenta desde arriba, desde el Estado, decir 'esto es la cultura tradicional oaxaqueña', el otro te está mostrando desde abajo lo que ellos piensan 'esto es nuestra cultura'... podemos hacer cuanto nos pegue en gana, pero nosotros estamos haciendo nuestra cultura, nos estamos empoderando".

En general, los estudiantes coincidieron en señalar que el comercial representaba a los sujetos "indígenas" como subalternos de los turistas de fenotipo europeo, lo cual sintetizó Celeste, estudiante de la Licenciatura en Lengua inglesa, al señalar: "en lugar de transmitirnos la idea de formar parte de la cultura, nos está poniendo, así como ahí están tus esclavos que te van a atender". También coincidieron en que eran representados como piezas decorativas para el disfrute de los turistas, y en ese sentido Antonio, estudiante de la Licenciatura en Sistemas computacionales administrativos, dijo: "vas ahí a verlos para turistear y no para estar con ellos... o sea, no para ser parte, sino ir como en el zoológico y disfrutar de todo eso”, y cuestionó: “¿en qué concepto tenemos a los indígenas?, ¿son nuestro entretenimiento o claramente personas de nuestra misma nación?"

5 El comercial (2014) promovía la Guelaguetza, fiesta popular que celebra las culturas "indígenas" del estado mexicano de Oaxaca (https://youtu.be/yxkEIU9orIM) y el cortometraje titulado Hamac Caziim: Fuego sagrado (2007) retrata un grupo de rock integrado por miembros del pueblo originario Comcaac, del estado de Sonora en el norte de México (https:// vimeo.com/107828518). 
Además, respaldaron el análisis que hizo Héctor, estudiante de Lengua y literatura hispánica, al contrastar el tratamiento visual y sonoro de ambas narraciones, mostrándose de acuerdo en que "en el comercial no hay rostros y no hay voces... pero en el otro... en cambio, los sujetos tienen rostro y no solamente son un rostro, sino que es una personalidad, porque se presentan frente a la cámara, con su rostro, con su ropa y con una música que seguro ellos eligieron para que los representara... hay una voz sobre su propia historia y... el porqué de lo que están haciendo, ¿no? Y en el otro nadie sabe por qué hacen lo que hacen... nada más están ahí".

Y coincidieron también en haber sentido más empatía por los personajes del cortometraje que por los del comercial; esto lo sintetizó Tania, estudiante de la Licenciatura en Química farmacéutica biológica al decir: "que ya marcar al indígena como un protagonista, como un personaje, hace que te sientas como muy relacionado hacia él... que incluso entres en la situación y quieras pertenecer... nunca uno de nosotros va a querer ser el indito que sale en la telenovela, pero sí va a querer ser el protagonista, ¿no?”

Por otra parte, considero significativo que los estudiantes hayan coincidido en señalar que, en las narrativas televisivas, los supuestos personajes "indígenas" suelen ser interpretados por actores "no indígenas"; al respecto Héctor dijo, exagerando un poco, que es común "que el indígena lo haga un vato a lo William Levy", un actor rubio de ojos azules. Mientras Irasema, estudiante de la Licenciatura en Fotografía, recordó una serie de comerciales conmemorativos del bicentenario de la Independencia de México: "un tipo de publicidad... de la mujer india, pero eran mujeres así súper europeas... vestidas como indias".

Considero significativo que tanto Flor como Raquel hayan señalado que antes de participar en los grupos focales del taller nunca habían reflexionado sistemáticamente acerca de las diferencias que existen entre las representaciones televisivas de "indígenas" y "españoles/güeros". A pesar de haber estudiado sociología, ser feministas y haber crecido consumiendo telenovelas como actividad familiar de ocio.

Ahora bien, en relación con los procesos de de-construcción y re-significación de imaginarios e identidades que detonó su participación en el taller, Flor asume que los grupos focales la llevaron a "pensar, reflexionar y de-construirse". Lo cual derivó en que al ver "que hay diferentes tipos de belleza" se sintiera más segura de sí misma, así como a cuestionar sus gustos, pues "antes cuando veía un chico güerito era como 'ay', pero ahora ya no, es así como... Ya no es lo mismo y ese creo que fue el cambio más repentino que tuve y más pronto".

Además, señaló que el proceso de cambio no ha sido radical sino sutil, y que más bien ha consistido en plantearse preguntas, en empezar a forjar una forma distinta de mirar, escuchar y entender el mundo: "en estos meses no te voy a decir, 'soy una mujer completamente diferente', pero... me sigo cuestionando, es como un empujón que te dan y ahí ya empiezas... a remar, remar y remar y vas cambiando" (E2, 08062015). 
Producto de esa forma distinta de ser en el mundo, Flor recordó que luego de analizar el comercial de la Guelaguetza, se dio cuenta de que parques temáticos como Xcaret hacen representaciones similares de "lo indígena" para promover una sensación de "qué bonito es ser mexicano", y que a partir de ser consciente de ello, cambió su forma de valorar ese tipo de parques y representaciones, "dije, no manches, ese parque me encanta y ya no lo voy a ver con esos mismos ojos, ya no voy a ir y lo voy a disfrutar de esa manera" (E2, 08062015).

Por su parte, Raquel considera que su participación en los grupos focales contribuyó a "sacarla de su burbuja" y enfrentarla a voces que la incomodaban y la sacaban de su "zona de confort"; que la llevaron a "poner en jaque" lo que daba por hecho, a cuestionar puntos de vista "que creía inamovibles", a darse cuenta de que "esas cosas que tenemos como tan certeras en nuestra vida, no lo son y... se pueden debatir" (E2, 23062015).

Coincidió con la mayor parte de sus compañeros en que casi todos los debates del módulo la llevaron a poner su atención y su capacidad de análisis en temas, situaciones y representaciones en las que no había reflexionado nunca, que la llevaron a ver "cosas que pueden parecer como muy obvias", a fijar su atención "más allá de lo superficial". Además, destacó que su participación la llevó a ser consciente de cómo el contexto específico desde el cual experimenta la vida incide en moldear sus imaginarios de un modo específico: "mis pensamientos no son alejados de la realidad en la que vivo; entonces, si lo pienso es por algo, entonces eso fue lo que me hizo darme cuenta" (E2, 23062015).

Explicó que, a su entender, en México no se habla de racismo por cuatro razones complementarias: 1) que "en México no hablamos de razas... hablamos de culturas, de pueblos", 2) que la palabra "racismo" remite a la de "raza", por lo cual, 3) preferimos emplear la palabra "discriminación" en lugar de la palabra "racismo" y, 4) que "tal vez esto del racismo sea más nombrado y... más visible en un lugar como Estados Unidos, donde tienen una raíz negra" (TR, 28112015).

Además, en el grupo focal de reflexividad, Raquel compartió sentirse comprometida y con ganas de convertir en prácticas sociales las reflexiones que desarrolló en el taller, con ganas de transformar la realidad en su entorno próximo, sus redes familiares y de amigos:

me siento como con mucha responsabilidad... de que todo eso que estamos ahorita compartiendo y que estoy leyendo y conociendo poderlo comunicar de la mejor manera, ¿no? Porque es todo un reto... que en mi familia pues sí... hay ideas racistas... no me lo puedo callar, pero también en qué línea está que si lo digo pues van a romper conmigo y ya no me van a querer escuchar, ¿no?... me siento en este momento como con ese compromiso, ¿no?... que todos estos conocimientos que traemos, cómo los dices para que también otra gente pueda decir, “ah, pues sí”... y no crear un discurso así de "bueno pues ya este... Pinches chavas radicales"... Ese no es mi objetivo... hay que buscar cómo acercarse (TR, 28112015). 
También considera que para enfrentar las desigualdades tal vez sea necesario ver los problemas no desde una mirada única, sino desde distintas perspectivas, porque "así como lo estamos viendo pues no hay salidas"; que tal vez sea necesario "mirar la otredad desde nuestras otredades... para que en efecto seamos una sociedad más incluyente" (E2, 23062015).

Finalmente, para describir las fronteras de lo propio y lo ajeno, y definirse a sí mismas, Flor y Raquel revelaron de qué modo construyen a los sujetos de identidad "indígena" y cómo se construyen a sí mismas en relación con sus imaginarios. Por ejemplo, al finalizar la primera entrevista con Flor, le pedí indicarme en qué medida y en qué orden de relevancia, se identificaba con cada una de las categorías de estudio, y destacó en primer lugar, "mestiza", luego "indígena", "negra", "española" y por último "mexicana"; y me explicó:

Indígena, yo lo dejaría como en segundo lugar y a éste en primero, mestizo; por los conceptos que se tienen, uno se imagina como indígena a alguien que no ha salido de su comunidad, que no se sabe mover en una ciudad, con pocos estudios, retraído, este, o sea, es lo primero que se me viene a la mente cuando leo la palabra indígena ¿no?, alguien que tiene que ser protegido. Entonces, yo no me siento así, o sea, yo me siento como te decía ahorita, como muy autónoma... lo interesante es que yo, físicamente, yo me considero muy indígena, o sea, más que mestiza... físicamente yo siento que perfecto encajo más como indígena que como mestiza... pero por eso me considero más mestiza, por este sentido de que, de cómo es mi relación con mi contexto, ¿no?, con esta urbanidad, que me sé mover.

Posteriormente, en nuestra segunda entrevista tres meses después, desde el imaginario que concibe posible la pureza de la "raza indígena" si se evita el mestizaje, y que emergió en el campo en voz de David, estudiante de la Licenciatura en Publicidad y relaciones públicas, le pregunté a Flor qué porcentaje de "indígena", "negra" y "española" consideraba tener en sí misma y respondió que $80 \%$ "indígena maya", $10 \%$ de "negra" y $10 \%$ de "española"; sin embargo, aclaró que no puede estar segura pues no conoce a su padre ni a su familia, pero aclaró con seguridad y orgullo que "culturalmente", por su familia materna "son más mayas que otra cosa".

Ahora bien, tomando en cuenta que Flor se asume físicamente "muy indígena", es notable que Olga, estudiante de la Licenciatura en Publicidad y relaciones públicas, no considere que el aspecto de Flor sea "indígena". Es notable que para explicar por qué no considera "indígena" su apariencia, haya dicho:

no digo que un indígena no pueda estudiar, pero... yo me imagino un indígena pues en su casa, tal vez como viviendo de lo que hace de cosecha, de animales, ese tipo de cosas... o sea, sí puede ir a la escuela, no digo que no, pero, por ejemplo Flor, que ya vive aquí, que va a un grupo de mujeres, no sé, feministas, o sea, como que esas no se me hacen actividades de indígenas, no sé por qué. 
Por otra parte, al finalizar la primera entrevista con Raquel, le pedí indicarme en qué medida y en qué orden de relevancia se identificaba con cada una de las categorías de estudio, y en el grupo focal de reflexividad compartió que al tener que elegir se sintió "en serios problemas identitarios", que se sintió confundida:

Me quedé, así como chale... entonces, ¿qué soy? Porque no me reconozco como indígena, pues ya no hablo la lengua, ya no practico todas estas cosas... aunque mis papás sí lo son, ¿no? Sin embargo, yo siento que mis fenotipos pues sí son de pueblos originarios... entonces sí tengo como problemas así de "no sé qué soy", pero creo que tiene que ver con todo este pasado de negación (ríe nerviosa).

Por ello, en la primera entrevista me dijo: "no me adscribo porque no, aunque yo tengo mucho cariño y eso, pero no crecí con ciertas cosas, con apego a la comunidad... no me siento como una estudiante indígena, no podría decirlo".

Me dijo que las categorías de estudio la describían con mayor precisión en este orden de relevancia: "mexicana", "indígena", "mestiza", "negra" y "española"; y tres meses después, en nuestra segunda entrevista cambió el orden y las acomodó de esta forma: "mestiza", "indígena", "mexicana", "negra" y "española". Sin embargo, volvió a cambiar el orden luego de que le pidiera señalar qué porcentaje de "indígena", "negra" y "española" considera tener en sí misma y respondiera que $70 \%$ de "indígena", $25 \%$ de "negra" y 5\% de "española". Entonces, me dijo que las categorías de estudio la describían con mayor precisión en este orden de relevancia: "indígena", "mexicana", "mestiza", "negra" y "criolla".

\section{Reflexiones finales}

La diversidad identitaria de los estudiantes hizo que, en las sesiones de grupo focal, Flor y Raquel se enfrentaran a puntos de vista radicalmente distintos a los propios. Las llevó a plantearse preguntas que nunca se habían planteado y a pensar en sí mismas y en los demás de formas novedosas, así como a reflexionar acerca del modo en que construyen lo propio y lo ajeno. Esto las llevó a visibilizar los patrones de inequidad que reproducían las representaciones analizadas, así como a que cuestionaran su legitimidad. Además, al contrastar las cualidades de las representaciones mediáticas estudiadas y visibilizar los objetivos políticos que les dan forma, las sesiones de grupo focal facilitaron nombrar el racismo que las estructura.

El proceso de investigación en su conjunto creó las condiciones para hacer visible la continuidad de ideas y acciones racistas en la vida cotidiana de los estudiantes a través del tiempo, así como para que valoraran positivamente interactuar en la diversidad, y afirmaran sus identidades con base en re-significar y re-valorar sus rasgos distintivos estigmatizados. Como resultado, visibilizó que los sujetos "indígenas" experimentan condiciones de desventaja, sometimiento y explotación con mayor frecuencia e intensidad que los "mestizos", porque los "mexicanos" no asumimos tener 
una forma racista de ver el mundo; sin embargo, el abuso simbólico y material contra los pueblos originarios es una práctica normalizada, ya que la igualdad que pretende garantizar la Constitución nacional "borra" de nuestra memoria que del periodo virreinal heredamos un tejido social fragmentado en castas y una estructura socioeconómica de dominación sobre "indígenas" y "negros".

Las acciones discriminatorias en contra de los "indígenas" son únicamente la punta de un iceberg. Lo que se encuentra debajo de la punta visible es un complejo sistema de representaciones simbólicas que establecen la jerarquía de dominación que justifica marginarlos. La gramática de identidad/alteridad nacional opera como prescripción racista de posiciones para sujetos y grupos. Su propósito político es legitimar el dominio "mestizo" sobre los pueblos originarios, atentando contra su dignidad al construirlos para disminuirlos, denigrarlos y negarlos, y opera de forma naturalizada, invisible, orientando las acciones de sujetos y grupos.

Para reproducir la gramática del sistema, la familia y la escuela son dos espacios de socialización de gran relevancia, por lo cual también son de vital importancia en los procesos de construcción identitaria de los sujetos. Sin embargo, en un contexto de lucha también es posible implementar procesos educativos que visibilicen desigualdades en la gramática de identidad/alteridad nacional, y que con base en la reflexión crítica contribuyan a construir una gramática nacional de identidad/alteridad plural y horizontal.

Para alcanzar ese objetivo, la educación popular, así como la educación intercultural y la educación para los medios en sus vertientes críticas, ofrecen las herramientas conceptuales y metodológicas necesarias para estructurar procesos educativos orientados a visibilizar y cuestionar desigualdades y los sistemas de dominación que las producen. Por ejemplo, de la educación popular (Freire, 2011) es útil retomar la estrategia pedagógica de problematizar la realidad como acción cultural para desmontar las estructuras de dominación.

La educación intercultural (Walsh, 2010) aporta la sensibilidad para identificar conflictos y construir soluciones con y desde la diversidad de forma situada, así como el objetivo de visibilizar las causas de asimetrías y desigualdades, pensar desde la perspectiva de los dominados y construir, en colaboración con ellos, conocimientos críticos al respecto. $\mathrm{Y}$ de la educación para los medios (Kellner y Share, 2007) tomamos la mirada crítica sobre la formación que ofrecen los medios de comunicación, así como la posibilidad de visibilizar conflictos de clase, raza, género, sexualidad y poder político desde múltiples perspectivas.

Así, lo que propongo llamar educación intercultural para los medios ha implicado formar a los estudiantes para desentrañar los significados que hay bajo la punta del iceberg; formarlos para navegar críticamente el mar de discursos textuales, orales, visuales y sonoros al que se enfrentan de forma cotidiana en todos los ámbitos de su vida. Crear ambientes de aprendizaje que los motiven a implantar formas de organización alternativas, gramáticas de identidad/alteridad que construyan relaciones sociales horizontales y dialógicas en la diversidad. Esto ha contribuido a de-construir procesos racistas de discriminación social y a detonar procesos de re-configuración identitaria ba- 
sados en la reflexión crítica acerca de las gramáticas de identidad/alteridad que subyacen a las representaciones sobre la diversidad.

\section{Referencias}

Anderson, B. (2005). Comunidades imaginadas, reflexiones sobre el origen y la difusión del nacionalismo. México: Fondo de Cultura Económica.

Bolivar, Antonio y Jesús Domingo (2006). "La investigación biográfica y narrativa en Iberoamérica: campos de desarrollo y estado actual". En: Forum: Qualitative Social Research. Vol. 7 , núm. 4. Berlín: Universidad Libre de Berlín.

Bonfil Batalla, G. (2010). México profundo, una civilización negada. México: Debolsillo.

Castellanos Guerrero, A. (2005). "Para hacer nación: discursos racistas en el México decimonónico”. En: Gómez Izquierdo, J. (coord). Los caminos del racismo en México. México: Plaza y Valdés, pp. 89-115.

Castoriadis, C. (2013). La institución imaginaria de la sociedad. México: Tusquets.

Cegarra, J. (2012). "Fundamentos teórico epistemológicos de los imaginarios sociales". En: Cinta Moebio, núm. 43. Santiago: Universidad de Chile, pp.1-13.

CONAPRED. (2011). Encuesta Nacional sobre Discriminación en México. ENADIS 2010. Resultados Generales. Consultado el 29 de abril de 2016 en: http://www.conapred.org.mx/userfiles/files/ Enadis-2010-RG-Accss-002.pdf

Dietz, G. (2012). Multiculturalismo, interculturalidad y diversidad en educación. Una aproximación antropológica. México: Fondo de Cultura Económica.

Freire, P. (2005). Pedagogía del oprimido. México: Siglo XXI.

Giménez, G. (2007). "Formas de discriminación en el marco de la lucha por el reconocimiento social”. En: Gall, O. (coord.). Racismo, mestizaje y modernidad: visiones desde latitudes diversas. México: UNAM.

(2009). Identidades sociales. México: Consejo Nacional para la Cultura y las Artes. Instituto Mexiquense de Cultura.

Gingrich, A. (2004). "Conceptualising Identities: anthropological alternatives to essentialising difference and moralizing about othering”. En: Baumann, G. y A. Gingrich (eds.). Grammars of Identity/Alterity: a Structural Approach. Londres: Bregan.

Gómez Izquierdo, J. (2005). "Racismo y nacionalismo en el discurso de las elites mexicanas: historia patria y antropología indigenista”. En: Gómez Izquierdo, J. (coord.). Los caminos del racismo en México. México: Plaza y Valdés.

y M. E. Sánchez Díaz de Rivera (2012). La ideología mestizante, el guadalupanismo y sus repercusiones sociales. México: UIA-BUAP.

González Casanova, P. (2003). Colonialismo interno: una redefinición. Conceptos y fenómenos fundamentales de nuestro tiempo. UNAM. Consultado el 29 de abril de 2016 en: http://conceptos.sociales.unam.mx/conceptos_final/412trabajo.pdf 
Gutiérrez Chong, N. (2001). Mitos nacionalistas e identidades étnicas: los intelectuales indígenas y el Estado mexicano. México: Consejo Nacional para la Cultura y las Artes /Plaza y Valdés.

Kellner, D. y J. Share (2007). "Critical media literacy, democracy, and the reconstruction of education”. En: Macedo, D. y S. R. Steinberg (eds.). Media Literacy: A Reader. Nueva York: Peter Lang Publishing.

Krieger, Peter. (2004). "La deconstrucción de Jacques Derrida (1930-2004)". Anales del Instituto de Investigaciones Estéticas, núm. 84, pp. 179-188.

Molina Valencia, N. (2013). "Discusiones acerca de la resignificación y conceptos asociados". En: Revista MEC-EDUPAZ, núm. III, pp. 39-63.

Ramírez Lozada, D. (2003). El amor a la patria en México, antropología de una pasión. México: BUAP.

Rockwell, E. (2009). La experiencia etnográfica: historia y cultura en los procesos educativos. Buenos Aires: Paidós.

Van Dijk, T. A. (2003). "La multidisciplinaridad del análisis crítico del discurso: un alegato en favor de la diversidad". En: Wodak, R. y M. Meyer. Métodos de análisis crítico del discurso. Barcelona: Gedisa.

Walsh, C. (2010). “Interculturalidad crítica y educación intercultural”. En: Viaña, J., L. Tapia y C. Walsh. Construyendo interculturalidad crítica. La Paz: III-CAB.

Recibido: 02/05/16

Dictaminado: 02/10/16

Corregido: 15/10/16

Aceptado: 19/10/16 